\title{
Environment 4.0: How digitalization and machine learning can improve the environmental footprint of the steel production processes $^{\text {th }}$
}

\author{
Valentina Colla ${ }^{1, *}$, Costanzo Pietrosanti ${ }^{2}$, Enrico Malfa $^{3}$, and Klaus Peters ${ }^{4}$ \\ ${ }^{1}$ Scuola Superiore Sant'Anna, TeCIP Institute, ICT-COISP Center, Pisa, Italy \\ ${ }^{2}$ Danieli Automation, Buttrio (UD), Italy \\ 3 Tenova S.p.A., Castellanza (VA), Italy \\ ${ }^{4}$ European Steel Technology Platform ASBL (ESTEP), Brussels, Belgium
}

Received: 4 October 2020 / Accepted: 4 February 2021

\begin{abstract}
The concepts of Circular Economy and Industrial Symbiosis are nowadays considered by policy makers a key for the sustainability of the whole European Industry. However, in the era of Industry4.0, this results into an extremely complex scenario requiring new business models and involve the whole value chain, and representing an opportunity as well. Moreover, in order to properly consider the environmental pillar of sustainability, the quality of available information represents a challenge in taking appropriate decisions, considering inhomogeneity of data sources, asynchronous nature of data sampling in terms of clock time and frequency, and different available volumes. In this sense, Big Data techniques and tools are fundamental in order to handle, analyze and process such heterogeneity, to provide a timely and meaningful data and information interpretation for making exploitation of Machine Learning and Artificial Intelligence possible. Handling and fully exploiting the complexity of the current monitoring and automation systems calls for deep exploitation of advanced modelling and simulation techniques to define and develop proper Environmental Decision Support Systems. Such systems are expected to extensively support plant managers and operators in taking better, faster and more focused decisions for improving the environmental footprint of production processes, while preserving optimal product quality and smooth process operation. The paper describes a vision from the steel industry on the way in which the above concepts can be implemented in the steel sector through some application examples aimed at improving socio-economic and environmental sustainability of production cycles.
\end{abstract}

Keywords: digitalization / Industry 4.0 / Artificial Intelligence / machine learning / steel industry / environmental footprint / carbon neutrality

\section{A view from the steel sector}

Nowadays, manufacturing and process industry, and steel sector in particular, is facing the global challenge of Sustainability. Sustainability is based on economic, environmental and social pillars expressed by the Sustainable Development Goals (SDGs) in 2030 the Agenda for Sustainable Development [1], which was adopted by all United Nations Member States in 2015. In addition to these three pillars, the effective implementation of the principles of Sustainable Manufacturing ${ }^{1}[2]$ must consider the high markets dynamics due to local instabilities or even exceptional events like the destructive COVID-19 pandemic, and the velocity of reaction needed at both business and operational levels.

\footnotetext{
4) 14th International Conference on Society \& Materials, SAM14, Bordeaux, 11-12 May 2020.

* e-mail: valentina.colla@santannapisa.it
}

In order to face the above-mentioned challenge, companies and plants should be run through a predictive approach, by managing stocks, orders and relationships with customers, while continuously improving environmental impact [3], as well as the other two pillars of profit and people [4]. Such optimal combination can generate profit to shareholders and richness to employees and neighboring communities, being green and safe at the same time [5].

Concerning the environmental pillar, steel industry in 2015 was responsible of $4 \%$ of $\mathrm{CO}_{2}$ emissions in Europe, with a specific $\mathrm{CO}_{2}$ emission average value of around $1300 \mathrm{~kg}$

\footnotetext{
1 Sustainable Manufacturing is the creation of manufactured products through economically-sound processes that minimize negative environmental impacts while conserving energy and natural resources. Sustainable manufacturing also enhances employee, community and product safety. https://www.epa. gov/sustainability/sustainable-manufacturing.
} 
$\mathrm{CO}_{2} / \mathrm{t}_{\mathrm{CS}}$ (ton of Crude Steel) between the $60 \%$ produced by the $\mathrm{BF} / \mathrm{BOF}$ route, and the $40 \%$ by EAF routes. Comparing such data to 1990 , the combined specific emissions (BF/ $\mathrm{BOF}+\mathrm{EAF}$ ) decreased by $14 \%$, while the corresponding reduction of total emission is in the order of $28 \%$.

In this context, Europe have fixed a reduction in total emissions with respect to 1990 of $40 \%$ in 2030 , and $95 \%$ in 2050 with reference to the carbon neutrality concept, i.e. the zero-net balance between emitted and released carbon into atmosphere [6].

These results could be achieved by developing and deploying a combination of different technologies ultimately leading to a climate-neutral steel industry, such as Carbon Direct Avoidance-CDA (e.g. use of green $\mathrm{H}_{2}$ as reducing agent of iron ore and fuel), use of energy from renewable sources directly in the EAF route or indirecty to generate geen- $\mathrm{H}_{2}$, Smart Carbon Usage - SCU (e.g. integration of new processes in current production routes, leading to reduced use of carbon), Carbon valorization/Carbon Capture and Usage \& Storage - CCS/CCUS, and promotion of Circular Economy (CE) and Industrial Symbiosis (IS) in different combinations. In addition, all the potential enablers providing improved flexibility, capability of self-reorganization of factors, automatic prediction of events and optimized reaction must significantly contribute to a timely achievement of the targets.

However, the two steps of 2030 and 2050 imply deployment of enabling factors, among which some important issues are not in charge of the steel industry. Two of them can be mentioned: availability of affordable carbon neutral electrical energy, and installation of efficient and effective grids, where energy providers and big users can negotiate their engagement. This is also the base for the availability of green $\mathrm{H}_{2}$ at competitive prices with respect to fossil sources, to provide the conditions to implement $\mathrm{H}_{2}$-based steelmaking technologies. In general, there are important challenges to consider, such as the potential demand generated to the envisioned large transition to $\mathrm{H}_{2}$. "This must be compared to the $\sim 70 \mathrm{TWh}$ of $H_{2} 2$ required to shift the 30 million tons of $C S$ produced in Germany via the BF /BOF route to H2 direct reduction in a shaft furnace. Moreover, the total energy consumption sums up to $\sim 120 \mathrm{TWh}$ of required green electricity to run the pelletizing plant, shaft furnace preheater, EAF and to account for conversion losses in the electrolyzer in addition to the required 70 TWh H2' [7]. These numbers are huge and need time and relevant economical efforts to be achieved, in addition to research, development and innovation risks.

The foreseen evolution will require also the capability of the European steel sector to gain a strong policy support to share the technological and economical risks [8], and a careful consideration of human-related aspects, including workforce upskilling and recruitment of new talents $[9,10]$.

Recently the European steel sector prepared for the socalled "Clean Steel Partnership" (CSP), a Public Private Partnership, which aims at managing the research activities to be developed under the umbrella of the Horizon Europe framework in order to develop breakthrough technologies for C-lean steel production. The overall purpose of this CSP is to face the challenge of sustainable growth and climate change, by preserving and enforcing the technological leadership of the European steel industry. The CSP roadmap [6] identifies digitalization as an enabler of the clean steel development and clearly states that an ever increasing exploitation of Artificial Intelligence (AI) and Machine Learning (ML) tools and techniques in order to handle the new process conditions and associated issues. Therefore, with respect to traditional steelmaking processes, which were development far beyond the advent of ML, the novel sustainable processes will exploit such tools from their early development. In particular, a huge potential exists for exploiting AI in order to improve the environmental impact of the steel production cycle, also considering the traditional routes and the implementation of CE and IS solutions.

\section{Bridging the gap to the vision}

Besides necessary economic efforts and technological risks, that are part of the challenges to face, several factors must be deployed in order to overcome the barriers and bridging the gap between the current situation and the vision of carbon-neutral steel industry. Among others, development of new steel manufacturing technologies, harmonized implementation of renewable sources for power generation, embracement of the $\mathrm{H}_{2}$ economy, development of new ecosystems based on $\mathrm{CE}$ and IS. For managing the envisaged transformation, a holistic combination of such factors is, therefore, necessary. In this context, Digitalization plays a key role in supporting new organizations and business models for managing this transformation, provides benefits from the complexity of the huge amount of information, by creating value from the "new oil" of data. It is expected to deal with such complexity by timely, efficiently and effectively monitoring, controlling and managing processes by implementing new flexible organizational models and integrated production management system, which will have relevant implications also for products and workforce [9].

Therefore, there are unstoppable trends towards extended sensorization of processes and data valorization. This is today empowered by development of standards for data exchange to allow interoperability of systems to be plugged into new architectures along the manufacturing chain and through the business chain, by thus breaking the barriers between Information Technology (IT) and Operational Technology (OT). Moreover, the rise of Intelligent Systems and Smart Networks using IoT/IIoT platforms and the diffusion of Platform Economy strongly support the implementation of CE and IS, by making valorization of residues into resources possible, with a consequent substantial reduction of global environmental impact and local pollution.

Data are at the basis of the digital transformation. Within the digital factory of the future a huge volume of heterogeneous and often non-structured data is collected from the different stages of the production chain as well as from external sources. This is made possible by the development of new sensors with embedded systems, which are capable to provide high sampling rates and contribute 
to the collection of large data volumes. Consequently, high power computing systems are necessary in order to make application of online Machine Learning (ML) techniques «at the edge of the application» possible, by providing fast data capitalization and exploitation of the created value.

In this scenario, for many industrial sectors, the importance of digital technology for reducing the environmental footprint of industrial cycles was analyzed [11-13]. The steel sector, for its part, very quickly reacts to new opportunities, having the advantage of starting from an already existing highly monitored and controlled production process, which can benefit from digitalization and related technologies, such as advanced modelling and simulation tools and ML, in order to reduce its environmental impact.

In the following sections, relevant literature results and some leading experiences coming from EU and public-funded projects are presented. In particular Section 3 provide a view on how the digital transformation can provide basic functionalities favoring the implementation of CE and IS solutions. Section 4 gives some exemplar projects where the previously described tools and concepts were put into practice. Section 5 overviews the next steps that need to be followed to make it possible a full exploitation of the digital technologies as a support to $\mathrm{CE}$ and IS in daily business of the steel sector.

\section{Enabling circular economy and industrial symbiosis through digital transformation}

The digital transformation of production processes allows collecting an ever-increasing volume of data, which can be processed and exploited to investigate, develop new business models, and practically implement CE and IS solutions [14].

The collected data can be exploited, for instance, in order to investigate the viability of novel processes by developing relevant models, to test them and related new operating practices, by thus paving the way to $\mathrm{CE}$ and IS solutions, for instance, aimed at decreasing the importance of secondary working operations to provide ready-to-sell resources, according to market requirements. A number of examples can be found in literature, where different kind of modelling tools are exploited after being tuned through process data in order to improve environmental sustainability of steelmaking processes, by enforcing resource and energy efficiency [15-18]. Such modelling tools can also be embedded into advanced monitoring systems for improving energy and resource efficiency at plant level $[19,20]$. The greater the capability to collect data which exhaustively represent the processes behaviors, the higher the possibility to exploit computationally efficient and data-driven models, which are often based on ML tools and techniques, such as Artificial Neural Networks (ANN) [21,22]. Sometimes, this kind of models are also exploited in order to mimic humans in the decision-making process to validate and test CE solutions [23], as well as to support the design phase [24-26].

However, digitalization is expected to play a further major role as enabler of CE and IS. The capability of a company to collect and process relevant volumes of heterogeneous data concerning its own processes, products and by-products can help fast and efficient provision or exchange of information with neighboring communities and other companies, paving the way to a cross-sectorial cooperation in facing common challenges, such as improvement of Energy and Resource Efficiency.

In effects, among the basic concepts behind IS, there is the fact that by-products, water, off-gas or energy streams coming from e.g. one company can be exploited by other companies and/or entities, including the surrounding community, which should take advantage from the resources and/or energy conveyed by those streams. If their features are remarkably variable (e.g. in terms of chemical or physical parameters, energy content or whatever), as it is very likely to occur in most practical situations, their possibilities of exploitation may vary through time. Therefore, firstly, suitable sensing and monitoring devices must be available, which collect as detailed information as possible on the considered streams, as the receiving processes/systems are most probably affected by instantaneous or short-term features, not by average ones.

Then, the collected information needs to be shared among the involved actors (e.g. companies and/or stakeholders involved in the streams exchange) in a safe and secure way, by verifying the integrity of such information. One of the key issues behind Big Data (which is also listed among the so-called "Vs" of Big Data, i.e. Volume, Variety, Velocity, Veracity, and, in some papers, also Validity and Volatility) refers to their veracity. In other words, the presence of outliers, biases, noise and any other forms of abnormality in data can hamper their meaningfulness with respect to the problem/ feature being monitored and/or analyzed. In case of data collected from sensor, data veracity also implies holding suitable means to enhance robustness with respect to sensor failures. ML is intensively applied for data cleansing and anomalous data detection. For instance, fuzzy inference systems are applied to combine different well-known approaches for identifying anomalous data $[27,28]$. As a further example, Auto-encoders are intensively used for data cleansing and outliers detection $[29,30]$, being capable to extract salient features of data, by avoiding to capture spurious and infrequent patterns; the extracted features are used to reconstruct a cleansed version of the signal, while outliers are identified by "comparing" original and cleansed data.

The collected information (which might be huge and heterogeneous) must be interpreted in a fast and efficient way. Here again the ML field provides a number of tools and techniques to extract meaningful interpretations and valuable knowledge from data. Just as an example, the large field of pattern analysis can be considered for extraction of meaningful combinations of factors leading to relevant events or phenomena to be identified [31] or controlled [32]. Variable selection [33] and feature extraction [34] techniques can provide a powerful support in order to identify the factors, which mostly affect a particular target, performance indicator [35], as well as the occurrence of faults and anomalies [36-38]. 
The collected data, together with process knowledge, can be further exploited in order to forecast basic features of the streams which are exchanged among the actors implementing an IS solution, in order to optimize their exploitation [39]. Here again ML can provide powerful tools, thanks to the capability to implement customizable models, which can self-adapt based on the available data. Moreover, advanced Multi-Objective Optimization (MOO) techniques [40] also bio-inspired (e.g. Evolutionary Computation) can be exploited to support human analyses [41] and decisions [42].

Finally, in order to be fruitful for all the involved workers and stakeholders, the outcomes of all the developed data analyses, interpretations as well as of the different optimization stages must be proposed in a practical and understandable way, by taking into account that plant managers and technical personnel are not necessary ICT specialists. To this aim, all the most updated technologies, such as advanced Human-Machine Interfaces and Augmented Reality (AR), can be exploited [43-45]. For instance, in literature the importance of exploiting Internet of Things (IoT), Virtual Reality (VR) and AR in remanufacturing is analyzed within the implementation of CE models [46].

\section{Exemplar applications of advanced simulation and machine learning for monitoring and control of the environmental footprint}

The importance of advanced simulation tools in order to improve the environmental footprint of the steel production processes was showed by several research projects. For instance, in the EU-funded project entitled "Efficient use of resources in steel plants through Process Integration" (ReffiPlant), advanced flowsheeting models were exploited in order to assess the viability of Process Integration solutions capable to improve by-products handling and water efficiency in integrated steelworks $[40,47,48]$. Such models were developed by means of the Aspen Plus ${ }^{\circledR}$ modelling and simulation suite and were tuned through process data, by minimizing the difference among the values of the monitored variables of the real and "virtual" processes. Within the RFCS project entitled "Cyanide Monitoring and Treatment under Dynamic Process Conditions" (DynCyanide), the same kind of models were tuned through Genetic Algorithms by exploiting experimental data to preliminary test and validate an innovative treatment for Blast Furnace (BF) gas washing waters [49].

Advanced modelling was coupled to environmental performance monitoring through Key Performance Indicators (KPI) within the EU-funded project entitled "Environmental impact evaluation and effective management of resources in the EAF steelmaking" (EIRES). This research activity focused on energy and resource efficiency, and the developed tools allow assessing different scenarios and operating conditions fostering an increased internal slag reuse [50], while considering the related costs in terms of electric energy consumptions [51]. In this case, Aspen
Plus ${ }^{\circledR}$ was exploited for the first time to model and simulate the entire electric steelmaking route up to the continuous caster and including water and gas networks. The different sub-models were validated by exploiting industrial data, and the overall simulation tool was linked to a metrics evaluation tool and a Life Cycle Analysis tool, which both output KPIs related to different aspects of the environmental impact [20]. The simulation models output the main energy and water consumptions, off-gases parameters, slag and steel chemical compositions, by facilitating joint consideration of product quality, process yield and efficiency, as well as environmental footprint-related variables.

Energy management is a further major relevant field of application for ML in the steel sector, by also considering the importance of joint process-energy management, which is highlighted in a number of recent studies [52]. The traditional production-driven approach, where the production is scheduled first, followed by energy supply optimization to find the best available energy portfolio, is usually sub-optimal. On the other hand, combined scheduling and energy procurement optimization, if formulated as an integrated monolithic optimization model, can result in intractable problems that require excessive computational time to be solved. It is therefore necessary to decompose the overall problem into "simpler" optimization problems, by eventually exploiting a hierarchical or decentralized approach. In this context, ML can provide powerful tool for both solving complex MOO problems and forecasting energy demands and production.

In an RFCS project entitled "Development of tools for reduction of energy demand and CO2 emissions within the iron and steel industry based on energy register, CO2 monitoring and waste heat power generation" (ENCOP), evolutionary computation was exploited for optimizing offgas distribution within integrated steelworks [53], by also considering the optimization of the gas network structure (i.e. the possibility to build or dismantle connections) [54]. In particular, the gas network was represented according to the concepts of graphs theory and the problem of off-gases management was treated as an optimization problem, where two objectives need to be jointly minimized, namely $\mathrm{CO}_{2}$ emissions and total cost, and the cost function includes also a term considering the cost of building new pipes and dismantling existing ones. This approach considered benefits and cost of retrofitting actions in the overall management, but its application field was limited by the lack of dynamic models for gases consumption and generation and, thus, could not be used for short-term control purposes.

Therefore, within a more recent EU-funded project on the same topic, entitled "Optimization of the management of the process gases network within the integrated steelworks" (GasNet) the issue of continuously monitoring [55] and optimizing the off gases distribution was faced. In this project, A Mixed-Integer Model Predictive Controller considering economic constraints and objectives was applied for optimizing the energy conveyed by the offgases in integrated steelworks [56]. A Mixed-Integer optimization problem is a problem where some of the variables to be optimized can take only integer values. 


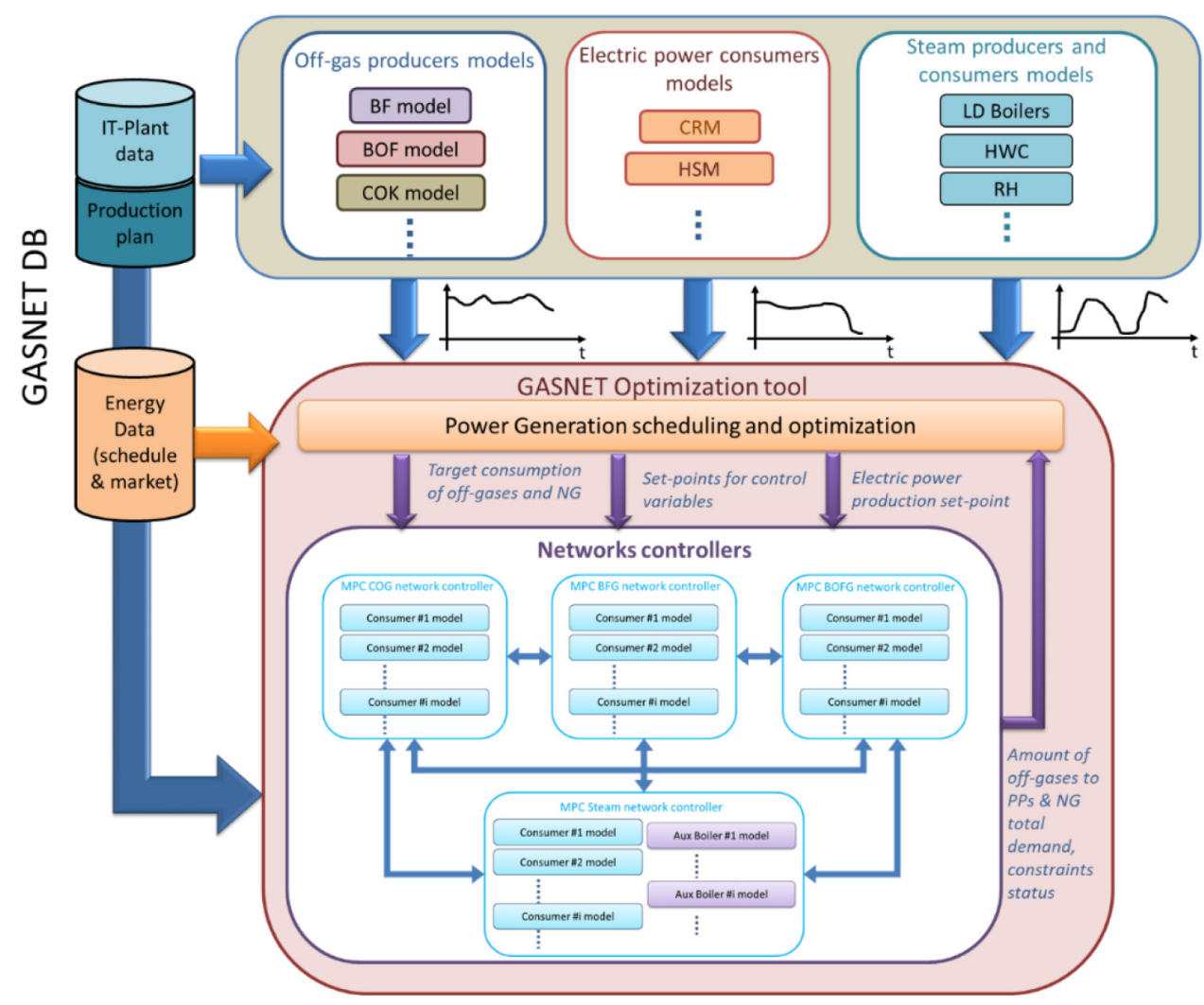

Fig. 1. Overview of the GasNet Optimization tool.

Model Predictive Control schemes exploit dynamic models of the process and develop an optimization on a finite time future horizon, then implement only the current timeslot, and afterwards optimize again, by thus showing the capability to anticipate future events and to take control actions accordingly [57]. In this project ML-based approaches were applied in order to forecast on a shortterm horizon off-gas production (and related energy content) and demand of different processes, including energy transformation equipment [58] (see Fig. 1). In particular, Echo-State Neural Networks (ESN) and Deep ESN (a specific recurrent ANN) proved to be very effective for modelling dynamic processes starting from process data, being also computationally efficient $[59,60]$. According to the overall structure depicted in Figure 1, the MLbased models are fed by plant data and provide the trends of gas production and energy demands for the incoming $2 \mathrm{~h}$ with a sampling rate of $1 \mathrm{~min}$ to the control system, i.e. a series of 120 values. Such system holds a hierarchical structure, as it is formed by a high level controller and several low lever controllers, one for each sub-network, i.e. BF Gas (BFG) network, Basic Oxygen Furnace Gas (BOFG) network, Coke Oven Gas (COG) network and steam network. The low level controllers are fed with the series of forecasted off-gas production and energy demand values and distribute the energy flows on the given prediction and control horizon by solving in real-time a Mixed Integer Linear Programming optimization problem [57] (namely an optimization problem, where a linear objective function must be maximized or minimized and some of the variables to optimize are integer). Each energy carrier network is sequentially optimized. On the other hand, the high level controller is characterized by a lower rate of the control action (every 15 minutes) and manages the power generation and overall minimization of costs by minimizing the purchase of natural gas and electricity and the amount of useful gas which is flared into torches.

Concerning the electric steelmaking cycle, in the ongoing Tenova/ORI Martin project "Lighthouse Plant Acciaio 4.0 ORI Martin Cyber Physical Factory" [61], which is funded by the Italian Ministry of Industrial Development (MISE), an ML-based system implements real-time control of the whole steel production cycle through complete plant digitalization, connectivity, and data exchange among machines and services. AI algorithms are applied in order to optimize the production process (such as schematically depicted in Fig. 2). The integration of the value-chain (supplier, manufacturer, technology partner and customer) is also a target of this project.

In the specific context of environmental targets and ecosystem integration, three actions have been undertaken: management of metallic scrap, which is the input of the process and characterize the CE nature of the EAF route; energy aware production planning, to be ready for the new energy market, and on-line LCA model, to valorize the environmental value of final products.

In this context, a Convolutional Neural Networks $(\mathrm{CNN})$, was developed in order to automatically classify the scrap category from truck images. The CNN holds 12 Layers with 5.5 Million parameters, is trained with 33.000 classified images of 7 different categories with resolution $640 \times 360$ pixel on an NVIDIA GeForce 1080Ti. 


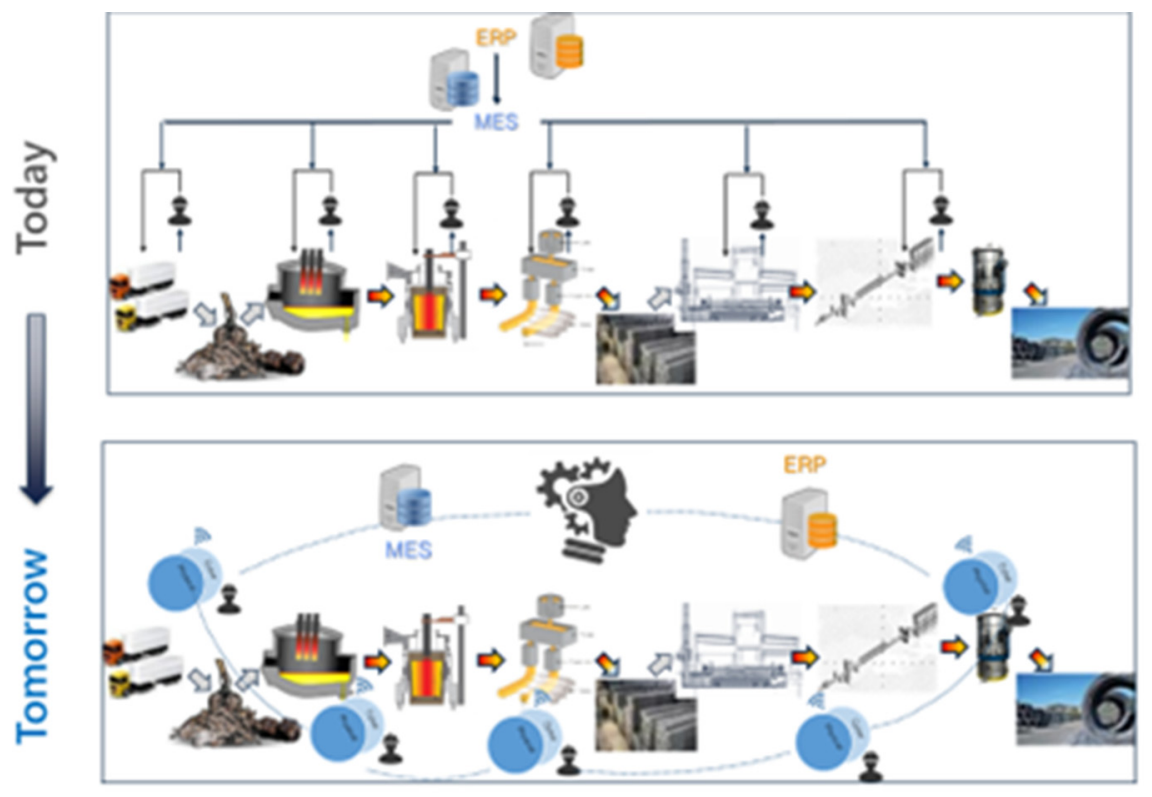

The entire production chain is

managed by different operators with

-Sub-optimal- solutions.

Such solution are based on the optimization of the individual

machines, which is often not the best process management strategy

\section{Artificial Intelligence Algorithm}

for the optimal and integrated

management of operational

contingencies.

Deviations from operating practices and the redefinition of sequences.

In an initial phase, the system suggest

to the operators the changes of

practice and / or settings to be made. without direct action

Fig. 2. The Lighthouse Plant Acciaio 4.0 project vision (courtesy of ORIMartin/Tenova).

\section{METAL SCRAP DELIVERY - Automatic Identification and Classification}

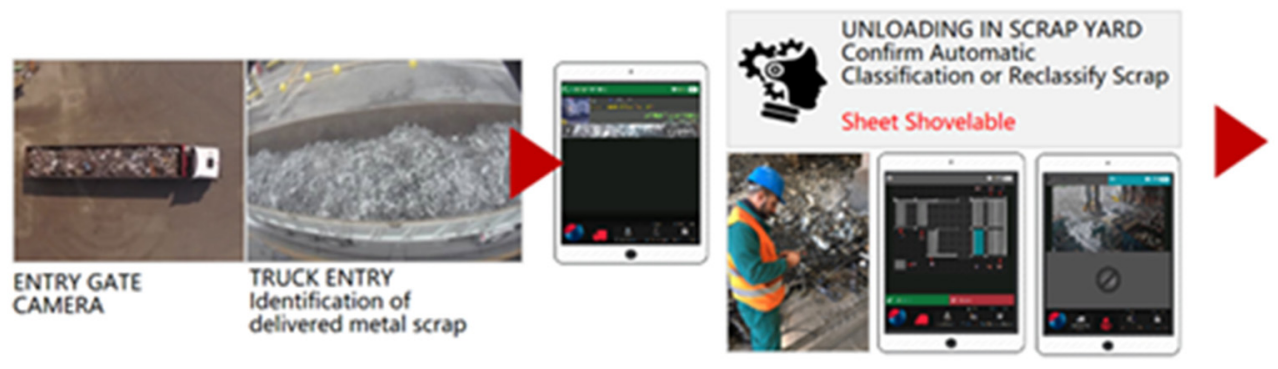

STORAGE AND COLLECTION - Material identified and tracked

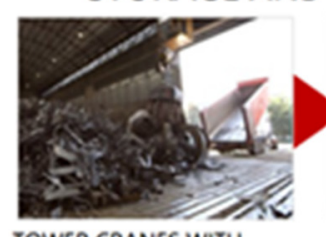

TOWER CRANES WITH INNOVATIVE WEIGHTING SYSTEM

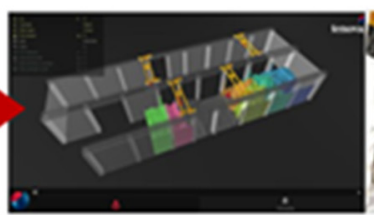

3D Laser profiling of volumes in storage area to drive loading and unloading operations
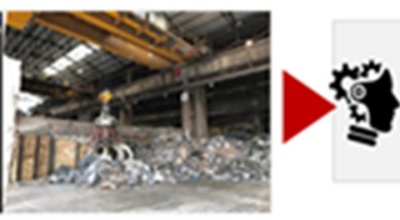

Missions to load the Consteel" with coordinates of where
to pick up the scrap

Fig. 3. Scrap tracking and identification system developed within the Lighthouse Plant Acciaio 4.0 project (courtesy of Tenova).

The truck at the plant entrance is identified through the image analysis of plate and classified according to the supplier. The category of truck load is then classified by the CNN-based system and compared to the material category as stated in the purchase order. A warning is issued on a tablet app of the yard operator if a mismatch is found. In such a case, the operator can take further actions to verify the actual steel category and quality, confirming, rejecting or re-classifying the scrap charge on the tablet app. The scrap is then unloaded in a set position on the shop floor, where cranes pick it up to place it in the dedicated storage area of the scrap yard. Each movement of the crane is tracked, so that it is possible to retrieve the type of scrap and its supplier from a given position in the storage area. A
3D Laser scanner is mounted on the cranes profiling the volumes in the storage area below to drive loading and unloading operations, creating a real time $3 \mathrm{D}$ map of all the scrap in the yard. The information regarding scrap, its supplier and its position in the yard is used to select the scrap to be loaded on the Consteel Continuous Charging System, which continuously feeds and pre-heats the metallic charge (scrap, pig iron, etc.) to the EAF (see Fig. 3) [62].

Within the same Lighthouse Plant Acciaio 4.0 project, a new generation software is under development targeting an energy aware production planning. Such software considers how the optimized model of production scheduling, with the additional constraint of minimization of 


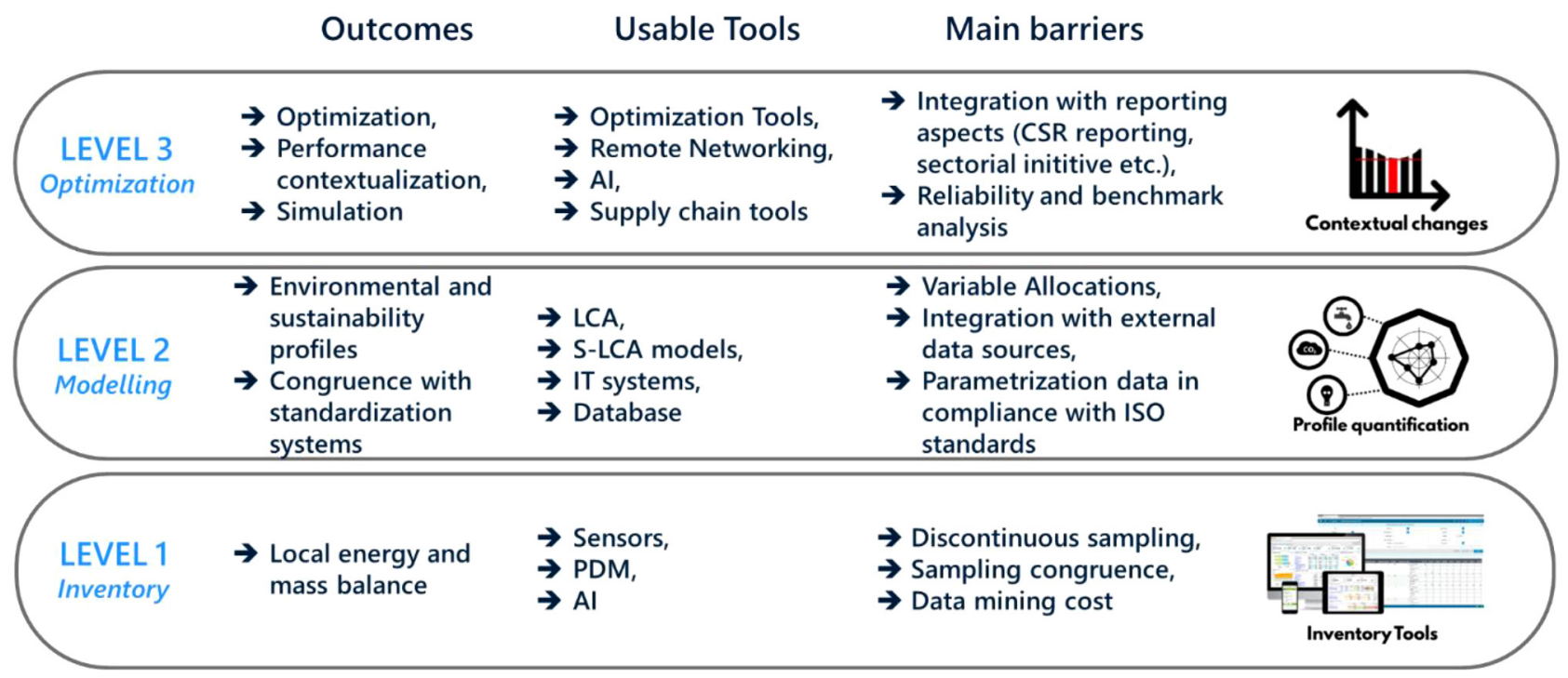

Fig. 4. Computational levels (courtesy of STIIMA-CNR partner of Lighthouse project).

energy cost, can take advantage from the opportunities offered by the energy market in the new scenarios and commitments, which are defined by the new European climate-energy package. The aimed advantages can be achieved by both optimizing of the modulation of the required power profile against energy hourly cost and exploiting the chance of real time negotiation on the Energy Market

An on-line LCA model is also being created, which is connected to both physical detection systems of environmental parameters and company data inventory systems at different levels [63], such as schematically represented in Figure 4. These packages will be integrated in the network of LightHouse added value services to provide:

- environmental monitoring of production process by LCA indicator allowing identification of critical path through reporting of global trends;

- sustainability reference process profiles for different batches and types of products;

- "environmental data-set" organized in accordance with specific sectoral standards ready and support environmental certification.

\section{Digitalization enables $C E$ and $I S$ in steel business: The next steps}

As said before, to give a significant contribution to decarbonization, the steel sector must achieve large extents of internal and external circularity and industrial symbiosis [64]. Nowadays Digitalization largely contributes to enable the achievement of this target within the process towards the target described by the Carbon Neutral Vision (see Sect. 2). Digitalization plays a key enabling role in this process. Therefore, a digital vision of the future steel factory is needed: the Smart Steel Factory, i.e. the ideal fully digitalized steel factory. According to the ESTEP' Vision statement (to be published in 2021), the Smart Steel
Factory is a safe and secure plant based on the integration of the factory automation into a network of connected intelligent and autonomous systems, humans and digital services. The Smart Steel Factory is capable to predict and self-adapt to market's needs, being respectful to the environment, by enabling full carbon neutral steel manufacturing and integrating production and humans toward production efficiency, while dynamically exploiting human expertise paired with machine capabilities.

To achieve such ambitious objectives, it is important to overcome barriers like:

a. The development and implementation of post-treatments and conditioning technologies for resides, to fit current and potential markets requirements.

b. The enhancement of process monitoring and control tools, by applying detection and predictive approaches, to the aim of providing workers with full awareness of process and quality evolution.

c. The friendly and controlled access to resource markets increasing trust and transparency through secure and fast transactions, as well as fast delivery of goods.

In this context, Digitalization is, directly or indirectly, among the key enablers of the above-mentioned goals. To be efficient and effective, the company processes (including existing and newly developed residues post-treatment solutions) must be integrated along the manufacturing chain to allow seamlessly exchanging and processing data, considering the states of the different areas and company functions.

Furthermore, it is worth saying that integration and the resulting increased complexity are strongly enabled by AIbased applications aimed at considering data and autonomously understanding the context through Machine Learning applications. This makes it possible to scale up local and extended optimization in manufacturing areas and the whole manufacturing chain, by enhancing forecasting capabilities and improving reactivity to events, including those involving external communities. So, the dramatic enhancement of capabilities is taking place today, 
and ever more will be in the future, considering the development and extensive implementation of continuous monitoring of operations, including the emissions evaluation, quasi-real time optimization of resource consumption, minimization of residues, and timely internal or third party's post-treatment and placement on the relevant markets. Reliability and efficiency depend by extensive AIbased applications, turning the approach, in many cases, from reactivity to predictivity.

From the technological point of view, point $b$ strictly depends on the deployment of new ICT architectures and related reference models. They have in common the possibility to transform the hierarchical structure of automation, process control, supervision and execution into a cooperative "System of Systems (SoS)", (systems, components and sensors), ensuring data to seamlessly flow "when, where and how" is necessary. The expected benefits of $S o S$ consist of significantly enhancing connectivity, interoperability and robustness of industrial networks. The achievement of such goals is supported by the diffusion and the advances of Industrial Internet of Things (IIoT) solutions and standards. IIoT and AI are expected to be among game-changers of the digital transformation toward the Smart Steel Factory. However, this transition needs time, because avoiding the increase of CAPEX and saving legacy systems as much as possible is mandatory, due to the large investments in ICT already done.

Within the pathway of the digital transformation, the enabling role of digitalization relevant to point $c$ makes it possible to fill the gap between steel plants and company context to markets, as well as to implement the Platform Economy $^{3}[65,66]$, by digitally connecting resource and secondary material customers with the steel sector.

Firstly, digital transactions through Platforms ensure: - Transparency, which is represented by the matching of secondary material requirements and real characteristics with availability. This is important for both internal circularity and transfer to external markets.

- Trust, security and confidentiality between customers and sellers.

Therefore, it is of utmost importance to timely access resource and secondary material markets by fitting customer requirements. For instance, scrap is internally recycled for a large extent in the steel sector instead, other types of residues must be normally post-treated in third party's plants. This can be the case of BF and BOF slags for construction sector, to be used as mineral admixture or partial replacement of cement improving mechanical and durability characteristics.

Secondly, it must be highlighted that the success of CE and IS depends on the satisfaction of quantitative and qualitative characteristics required by markets. Then, scrap and secondary materials, belonging to the category of commodities, compete primarily on price and promise. In

\footnotetext{
2 The System of Systems is a collection of task-oriented or dedicated systems that pool their resources and capabilities together to create a new, more complex system which offers more functionality and performance than simply the sum of the constituent systems.
}

the Platform Economy, players (mainly vendors and customers) meet through digital platforms having several alternatives for orders/selling, which are secured by the strict control of identity, exchanging money under the supervision and protection of cybersecurity "umbrella", such as Blockchain. Furthermore, Platforms amplify the benefit of embracing new models, such as the "as a service" business model $[67]^{4}$. This leads to accelerate transactions by deploying their large potential to reduce costs through the superior velocity of current and future Internet, and by ensuring information confidentiality also in cloud environments.

To conclude, the sustainable transformation of society and the steel sector inside the industrial context, considers digitalization as a "must have" to fill the gap between today and the vision of the full sustainable steel manufacturing, and to deal with the ever-growing complexity and variety of scenarios to be managed, including $\mathrm{CE}$ and IS, by allowing the achievement of the large contribution needed and expected.

\section{Conclusions}

Digitalization in general and AI \& ML in particular have a great potential in supporting the improvement of the environmental footprint of steel production processes. Digitalization is fundamental because the implementation of monitoring, control and optimization systems, is obligatory to improve the processes management in the light of increasingly more complex systems. This holds for both traditional production processes and for innovative ones, which are being and will be developed in order to explore novel production paths for carbon-neutral steel production using Direct Carbon Avoidance and Smart Carbon Usage. Moreover, digital technologies are fundamental enablers for the implementation of advanced CE and IS solutions, as they allow duly monitoring and tracking of exchanged resource and energy streams as well as supporting human decisions.

The steelworks of the future might take great economic and environmental advantages from the exploitation of all the advanced tools and techniques connected to the digitalization of the production process, by preserving the centrality of the human role. The leading role in decision-making will remain in the hands of operators and managers. However, decisions will be taken on the basis of a complete and updated overview of the process conditions, relieving humans from cumbersome and repetitive operations.

\footnotetext{
3 Platforms are digital tools that match the requirements of potential customers with the characteristics of goods and provide secure environment for B2B transactions. Examples are the platforms of Amazon, AirBnB etc.

4 As a service business model is characterized by payment and delivery options, which purchase access to products as a service, by flexibly modulating quantities and characteristics according to the needs (a revision of the definition given in [66]) .
} 
As data and information storage and safe and secure sharing and exchange among different actors inside and outside the perimeter of the steelworks is an integral part of the digitalization process and of the exploitation opportunities it can convey, clearly the issue of cybersecurity and all the associated risks are crucial and need to be adequately faced. This aspect still represents a major barrier for the getting full advantages of the ongoing digital transformation and relevant efforts will be spent in order not only to implement adequate technological solutions but also to provide workers of any level with adequate skills, by creating a "culture of cybersecurity", similarly to what was and is being effectively done for security and safety.

\section{References}

1. United Nations, Transforming our world: the 2030 Agenda for Sustainable Development, 2015, https://sdgs.un.org/ 2030agenda (last access January 23, 2021)

2. J.-P. Birat, E. Malfa, V. Colla, J.S. Thomas, SUSTAINABLE steel production for the 2030s: The vision of the European Steel Technology Platform's Strategic Research Agenda (ESTEP's SRA), in: Technical Proceedings of the2014 NSTI Nanotechnology Conference and Expo, NSTI-Nanotech 2014, Vol. 3, 2014, pp. 238-241

3. A.N. Conejo, J.-P. Birat, A. Dutta, A review of the current environmental challenges of the steel industry and its value chain, J. Environ. Manag. 259, article no. 109782 (2020)

4. J.-P. Birat, Society, materials, and the environment: The case of steel, Metals 10(3), art. no. 331 (2020)

5. J.-P. Birat, The environment and materials, from the standpoints of ethics, social sciences, law and politics, Materiaux \& Techniques 107(1), art. no. 102 (2019)

6. https://www.estep.eu/assets/Uploads/ec-rtd-he-partner ships-for-clean-steel-low-carbon-steelmaking.pdf (last access January 17, 2021)

7. FOCUS Roland Berger, "The future of steelmaking - How the European steel industry can achieve carbon neutrality", in: Roland Berger GMBH, May 2020, 2020

8. M. Arens, Policy support for and R\&D activities on digitising the European steel industry, Resour. Conserv. Recycl. 143, 244-250 (2019)

9. T.A. Branca, B. Fornai, V. Colla, M.M. Murri, E. Streppa, A. J. Schröder, The challenge of digitalization in the steel sector, Metals 10(2), art. no. 288 (2020)

10. T. Akyazi, A. Oyarbide, A. Goti, J. Gaviria, F. Bayon, Creating a roadmap for professional skills in industry 4.0, Hydrocarb. Process. 99(11), (2020)

11. A.B.L. de Sousa Jabbour, C.J.C. Jabbour, C. Foropon, M.G. Filho, When titans meet - Can industry 4.0 revolutionise the environmentally-sustainable manufacturing wave? The role of critical success factors, Technol. Forecast. Social Change 132, 18-25 (2018)

12. Y. Li, J. Dai, L. Cui, The impact of digital technologies on economic and environmental performance in the context of industry 4.0: A moderated mediation model, Int. J. Prod. Econ. 229, article no. 107777 (2020)

13. K. Tiwari, M. Khan S., Sustainability accounting and reporting in the industry 4.0, J. Clean. Prod. 258, (2020)

14. V. Colla, Empowering steel manufacturing through Artificial Intelligence and Machine Learning, in: AI \& Big Data for Innovation Summit, December 2-5 2019, organised by the
K4I Forum in the European Parliament, Brussels (Belgium), 2019

15. G.F. Porzio, V. Colla, B. Fornai, M. Vannucci, M. Larsson, H. Stripple, Process integration analysis and some economicenvironmental implications for an innovative environmentally friendly recovery and pre-treatment of steel scrap, Appl. Energy 161, 656-672 (2016)

16. I. Matino, T.A. Branca, B. Fornai, V. Colla, L. Romaniello, Scenario analyses for by-products reuse in integrated steelmaking plants by combining process modeling, simulation, and optimization techniques, Steel Res. Int. 90(10), art. no. 1900150 (2019)

17. V. Colla, I. Matino, F. Cirilli, et al., Improving energy and resource efficiency of electric steelmaking through simulation tools and process data analyses, Materiaux \& Techniques 104(6-7), article no. 602 (2016)

18. C. Schneider, S. Lechtenböhmer, Industrial site energy integration - The sleeping giant of energy efficiency? Identifying site specific potentials for vertical integrated production at the example of German steel production, in: Eceee Industrial Summer Study Proceedings, 2016, pp. 587-598

19. V. Colla, F. Cirilli, B. Kleimt, et al., Monitoring the environmental and energy impacts of electric arc furnace steelmaking, Materiaux \& Techniques 104(1), art. no. 104 (2016)

20. I. Matino, E. Alcamisi, V. Colla, S. Baragiola, P. Moni, Process modelling and simulation of electric arc furnace steelmaking to allow prognostic evaluations of process environmental and energy impacts, Materiaux \& Techniques 104(1), art. no. 10 (2016)

21. V. Colla, I. Matino, S. Dettori, S. Cateni, R. Matino, Reservoir computing approaches applied to energy management in industry, Commun. Comput. Inform. Sci. 1000, 66$79(2019)$

22. X. Chen, J. She, X. Chen, Wu M., Discrete wavelet transfer based BPNN for calculating carbon efficiency of sintering process, J. Adv. Comput. Intell. Intell. Inform. 20(7), 10701076 (2016)

23. M. Lieder, F.M.A. Asif, A. Rashid, A choice behavior experiment with circular business models using machine learning and simulation modeling, J. Clean. Prod. 258, article no. 120894 (2020)

24. V.J.L. Gan, I.M.C. Lo, J. Ma, K.T. Tse, J.C.P. Cheng, C. Chan M., Simulation optimisation towards energy efficient green buildings: Current status and future trends, J. Clean. Prod. 254, article no. 120012 (2020)

25. J. Varghese J., Computational design of catalysts for biowaste upgrading, Curr. Opin. Chem. Eng. 26, 20-27 (2019)

26. M. Vondra, M. Touš, S.Y. Teng, Digestate evaporation treatment in biogas plants: A techno-economic assessment by Monte Carlo, neural networks and decision trees, J. Clean. Prod. 238, article. no. 117870 (2019)

27. S. Cateni, V. Colla, G. Nastasi, A multivariate fuzzy system applied for outliers detection, J. Intell. Fuzzy Syst. 24(4), 889-903 (2013)

28. S. Cateni, V. Colla, M. Vannucci, A fuzzy logic-based method for outliers detection, in: Proceedings of the IASTED International Conference on Artificial Intelligence and Applications, AIA 2007, 2007, pp. 561-566

29. M. Sakurada, T. Yairi, Anomaly detection using autoencoders with nonlinear dimensionality reduction, in: Proceedings of the MLSDA 2014, 2nd Workshop on Machine Learning for Sensory Data Analysis, 2014, pp.4-11 
30. C. Zhou, R.C. Paffenroth, Anomaly detection with robust deep autoencoders, in: Proceedings of the 23rd ACM SIGKDD International Conference on Knowledge Discovery and Data Mining, 2017, pp. 665-674

31. I.-C. Wu, T.-L. Chen, Y.-M. Chen, T.-C. Liu, Y.-A. Chen, Analyzing load profiles of electricity consumption by a time series data mining framework, in: Lecture Notes in Computer Science (including subseries Lecture Notes in Artificial Intelligence and Lecture Notes in Bioinformatics), 10294 LNCS, 2017, pp. 443-454

32. X.-L. Li, D.-X. Liu, C. Jia, X.-Z. Chen, Multi-model control of blast furnace burden surface based on fuzzy SVM, Neurocomputing 148, 209-215 (2015)

33. S. Cateni, V. Colla, M. Vannucci, General purpose input variables extraction: A genetic algorithm based procedure GIVE a GAP, in: ISDA 2009, 9th International Conference on Intelligent Systems Design and Applications, 2009, pp. $1278-1283$

34. V. Bolón-Canedo, B. Remeseiro, B. Cancela, Feature Selection for Big Visual Data: Overview and Challenges, in: Lecture Notes in Computer Science (including subseries Lecture Notes in Artificial Intelligence and Lecture Notes in Bioinformatics), 10882 LNCS, 2018, pp. 136-143

35. S.K. Phan, C. Chen, Big Data and Monitoring the Grid, The Power Grid: Smart, Secure, Green and Reliable, 2017, pp. 253-285

36. J. Pence, Y. Sun, X. Zhu, Z. Mohaghegh, C. Ostroff, E. Kee, Data-theoretic methodology and computational platform for the quantification of organizational mechanisms in probabilistic risk assessment, in: International Topical Meeting on Probabilistic Safety Assessment and Analysis, PSA 2017, Vol. 2, 2017, pp. 1294-1300

37. S. Cateni, V. Colla, M. Vannucci, A genetic algorithm-based approach for selecting input variables and setting relevant network parameters of a SOM-based classifier, Int. J. Simul.: Syst. Sci. Technol. 12(2), 30-37 (2011)

38. S. Cateni, V. Colla, M. Vannucci, A hybrid feature selection method for classification purposes, in: Proceedings - UKSimAMSS 8th European Modelling Symposium on Computer Modelling and Simulation, EMS 2014, 2014, pp. 39-44

39. I. Matino, S. Dettori, V. Colla, V. Weber, S. Salame, Forecasting blast furnace gas production and demand through echo state neural network-based models: Pave the way to off-gas optimized management, Appl. Energy 253, article no. 113578 (2019)

40. I. Matino, V. Colla, T.A. Branca, L. Romaniello, Optimization of By-Products Reuse in the Steel Industry: Valorization of Secondary Resources with a Particular Attention on Their Pelletization, Waste Biomass Valoriz. 8(8), 2569-2581 (2017)

41. Z. Yeo, J.S.C. Low, D.Z.L. Tan, S.Y. Chung, T.B. Tjandra, J. Ignatius, A collaboration platform for enabling industrial symbiosis: Towards creating a self-learning waste-to-resource database for recommending industrial symbiosis transactions using text analytics, Proc. CIRP 80, 643-648 (2019)

42. G.F. Porzio, B. Fornai, A. Amato, et al., Reducing the energy consumption and $\mathrm{CO}_{2}$ emissions of energy intensive industries through decision support systems-An example of application to the steel industry, Appl. Energy 112, 818-833 (2013)

43. E. Arica, M. Oliveira, C. Emmanouilidis, Performance measurement in sensorized sociotechnical manufacturing environments, in: IFIP Advances in Information and Communication Technology, Vol. 536, 2018, pp. 263-268
44. M. Oliveira, E. Arica, M. Pinzone, P. Fantini, M. Taisch, Human-Centered Manufacturing Challenges Affecting European Industry 4.0 Enabling Technologies, in: Lecture Notes in Computer Science (including subseries Lecture Notes in Artificial Intelligence and Lecture Notes in Bioinformatics), 11786 LNCS, 2019, pp. 507-517

45. E.G. Almquist, Implementation of MANIFEST augmented reality system at tata steel Europe, in: AISTech - Iron and Steel Technology Conference Proceedings, Vol. 3, 2020, pp. $1734-1744$

46. M. Kerin, D.T. Pham, A review of emerging industry 4.0 technologies in remanufacturing, J. Clean. Prod. 237, (2019)

47. I. Matino, V. Colla, L. Romaniello, F. Rosito, L. Portulano, Simulation techniques for an efficient use of resources: an overview for the steelmaking field, in: 2015 World Congress on Sustainable Technologies, WCST 2015, 2016, pp. 48-54

48. V. Colla, I. Matino, T.A. Branca, B. Fornai, L. Romaniello, F. Rosito, Efficient use of water resources in the steel industry, Water 9(11), article no. 874 (2017)

49. I. Matino, V. Colla, T.A. Branca, Extension of pilot tests of cyanide elimination by ozone from blast furnace gas washing water through Aspen Plus ${ }^{\circledR}$ based model, Front. Chem. Sci. Eng. 12(4), 718-730 (2018)

50. I. Matino, V. Colla, S. Baragiola, Internal Slags Reuse in an Electric Steelmaking Route and Process Sustainability: Simulation of Different Scenarios Through the EIRES Monitoring Tool, Waste Biomass Valoriz. 9(12), 24812491 (2018)

51. I. Matino, V. Colla, S. Baragiola, Electric energy consumption and environmental impact in unconventional EAF steelmaking scenarios, Energy Proc. 105, 3636-3641 (2017)

52. D.C. Mazur, J.A. Kay, K.D. Mazur, B.K. Venne, The value of integrating power and process for the metals industry, Iron Steel Technol. 15(5), 56-62 (2018)

53. G.F. Porzio, G. Nastasi, V. Colla, M. Vannucci, T.A. Branca, Comparison of multi-objective optimization techniques applied to off-gas management within an integrated steelwork, Appl. Energy 136, 1085-1097 (2014)

54. A. Maddaloni, G.F. Porzio, G. Nastasi, V. Colla, T.A. Branca, Multi-objective optimization applied to retrofit analysis: A case study for the iron and steel industry, Appl. Therm. Eng. 91, 638-646 (2015)

55. V. Colla, I. Matino, S. Dettori, et al., Assessing the efficiency of the off-gas network management in integrated steelworks, Materiaux \& Techniques 107(1), art. no. 104 (2019)

56. A. Wolff, F. Mintus, S. Bialek, S. Dettori, V. Colla, "Economical Mixed-Integer Model Predictive Controller for optimizing the sub-network of the BOF gas", in: European Steel Days ESTAD 2019, June 24-28, 2019, Dusseldorf (Germany)

57. E.F. Camacho, C. Bordons, Introduction to model predictive control, Adv. Textb. Control Signal Process. 1-11 (2007)

58. S. Dettori, I. Matino, V. Colla, V. Weber, S. Salame, Neural network-based modeling methodologies for energy transformation equipment in integrated steelworks processes, Energy Proc. 158, 4061-4066 (2019)

59. V. Colla, I. Matino, S. Dettori, S. Cateni, R. Matino, Reservoir computing approaches applied to energy management in industry, Commun. Comput. Inform. Sci. 1000, 6679 (2019)

60. I. Matino, S. Dettori, V. Colla, V. Weber, S. Salame, Two innovative modelling approaches in order to forecast consumption of blast furnace gas by hot blast stoves, Energy Proc. 158, 4043-4048 (2019) 
61. https://www.innovationpost.it/2019/04/01/lacciaieria-intel ligente-che-diventa-un-impianto-faro/

62. G. Bavestrelli, Metal Scrap Classification and Tracking at Ori Martin, in: Proc. of the Workshop on Green Steel by the EAF route, November 13-14, 2019, Bergamo (Italy)

63. A. Ballarino, C. Brondi, A. Brusaferri, G. Chizzoli, The CPS and LCA modelling: An integrated approach in the environmental sustainability perspective, IFIP Adv. Inform. Commun. Technol. 506, 543-552 (2017)

64. "Circular Economy Action Plan: For a cleaner and more competitive Europe" within the framework of the
"European Green Deal", European Commission, 2020, https://ec.europa.eu/info/strategy/priorities-2019-2024/ european-green-deal/actions-being-taken-eu_en (last access January 23, 2021)

65. S. Popper, S. Bankes, R. Callaway, D. DeLaurentis, in: System-of-Systems Symposium: Report on a Summer Conversation, July 21-22, 2004, Potomac Institute for Policy Studies, Arlington, VA

66. A. Moazed, Modern Monopolies, Macmillan, 2016, $30 \mathrm{p}$.

67. https://www2.deloitte.com/us/en/insights/topics/strate gy/as-a-service-business-model-flexible-consumption.html (last access January 27, 2021)

Cite this article as: Valentina Colla, Costanzo Pietrosanti, Enrico Malfa, Klaus Peters, Environment 4.0: How digitalization and machine learning can improve the environmental footprint of the steel production processes, Matériaux \& Techniques 108, 507 $(2020)$ 